\title{
Inhaled Phosphodiesterase 4 (PDE4) Inhibitors for Inflammatory Respiratory Diseases
}

\author{
Jonathan E. Phillips* \\ Department of Inflammation Research, Amgen Research, Thousand Oaks, CA, United States
}

PDE4 inhibitors can suppress a variety of inflammatory cell functions that contribute to their anti-inflammatory actions in respiratory diseases like chronic obstructive pulmonary disease (COPD) and asthma. The systemically delivered PDE4 inhibitor roflumilast has been approved for use in a subset of patients with severe COPD with chronic bronchitis and a history of exacerbations. Use of systemically delivered PDE4 inhibitors has been limited by systemic side effects. Inhaled PDE4 inhibitors have been considered as a viable alternative to increase tolerability and determine the maximum therapeutic potential of PDE4 inhibition in respiratory diseases.

\section{OPEN ACCESS}

Keywords: asthma, COPD, inhalation, CHF6001, pulmonary

Edited by:

Juraj Mokry,

Comenius University in Bratislava,

Slovakia

Reviewed by:

Sabina Antonela Antoniu,

Grigore T. Popa University of Medicine and Pharmacy, Romania

Fabrizio Facchinetti,

Chiesi Farmaceutici, Italy

*Correspondence:

Jonathan E. Phillips

jonathan.phillips@amgen.com

Specialty section:

This article was submitted to

Respiratory Pharmacology,

a section of the journal

Frontiers in Pharmacology

Received: 12 December 2019

Accepted: 24 February 2020

Published: 12 March 2020

Citation:

Phillips JE (2020) Inhaled Phosphodiesterase 4 (PDE4)

Inhibitors for Inflammatory Respiratory

Diseases. Front. Pharmacol. 11:259.

doi: 10.3389/fphar.2020.00259

\section{INTRODUCTION}

Phosphodiesterase (PDE) enzymes metabolize the intracellular second messengers cyclic adenosine monophosphate (cAMP) and cyclic guanosine monophosphate (cGMP). The PDE superfamily of enzymes contains 11 gene families (PDE1 to PDE11), most of which contain several PDE genes (Baillie et al., 2019). PDE4 enzymes are a family of four genes (PDE4A-D) within the PDE superfamily which specifically hydrolyze the $3^{\prime}, 5^{\prime}$ phosphodiester bond of cAMP to yield $5^{\prime}$ adenosine monophosphate (5'-AMP). PDE inhibitors have been intensely investigated for airway inflammation due to the clinical efficacy of the non-selective PDE inhibitor theophylline (Krzanowski and Polson, 1988). The expression of PDE4 has been demonstrated in many of the inflammatory cells (T-cells, eosinophils, neutrophils, monocytes, and others) relevant in asthma and COPD (Page, 2014). Therefor PDE4 inhibitors are an effective therapeutic strategy for inflammatory respiratory diseases as they inhibit the hydrolysis of cAMP (Rall and Sutherland, 1958), effectively increasing levels of cAMP, and activating downstream phosphorylation cascades (Li et al., 2018) which relax airway smooth muscle and inhibit inflammation (Houslay et al., 2005; Mulhall et al., 2015).

Three PDE4 inhibitor drugs are currently approved for the treatment of skin or lung diseases: apremilast, crisaborole, and roflumilast. Roflumilast is currently the only PDE4 inhibitor approved for the treatment of a subset of patients with severe COPD. In large clinical trials, roflumilast significantly improved lung function and reduced the rate of exacerbations in patients with severe COPD (Calverley et al., 2009), especially when added to long acting bronchodilators (Fabbri et al., 2009). In a COPD 'chronic bronchitis' responder group, namely those suffering from severe airflow obstruction with symptoms of chronic cough and sputum and a history of previous exacerbations, Roflumilast was approved by the FDA in 2011 despite its relatively poor tolerability (Cazzola et al., 2016). Roflumilast has also been studied in asthma and while it has no effect on the acute phase response (bronchoconstriction), it attenuates the late phase 
asthmatic response and prevents the subsequent increase in bronchial reactivity following an allergen challenge (van Schalkwyk et al., 2005; Louw et al., 2007). Although PDE4 is present in airway smooth muscle cells, selective PDE4 inhibitors have not demonstrated acute bronchodilator effects in humans (Boswell-Smith et al., 2006). The change in $\mathrm{FEV}_{1}$ seen in the late phase response is thus mostly due to the resolution of underlying airway inflammation. The primary problem with oral PDE4 inhibitors is the low therapeutic index of these compounds, which severely limits the dose that can be given. Mechanism based adverse effects include nausea, emesis, diarrhea, and headache. It is likely that the maximum tolerated dose of roflumilast is near the bottom of the efficacy dose-response curve.

A potential approach to improve the therapeutic index of orally bioavailable PDE4 inhibitors is to direct the PDE4 subtype selectivity toward PDE4B which accounts for many of the anti-inflammatory effects (Ariga et al., 2004) and away from PDE4D which is related to emesis (Robichaud et al., 2002). It has been demonstrated that a non-subtype selective PDE4 inhibitor like roflumilast has a better therapeutic index that a PDE4D selective inhibitor like cilomilast (Baillie et al., 2019). Unfortunately, no selective PDE4B inhibitors have advanced to clinical trials (Fox et al., 2014). Selectively targeting the lowaffinity rolipram-binding site conformer of PDE4 over the highaffinity rolipram-binding conformer (LARBS/HARBS) has also been suggested to reduce the side effects of PDE4 inhibitors (Moretto et al., 2015).

Inhaled administration represents another potential approach to improve the therapeutic index of PDE4 inhibitors. Many PDE4 inhibitors have been designed for inhaled administration in respiratory diseases. A few of these inhaled PDE4 inhibitors have advanced into clinical trials for treatment of asthma and COPD. The inhaled PDE4 inhibitors have been previously reviewed (Yeadon et al., 2010; Tenor et al., 2011; Matera et al., 2014; Mulhall et al., 2015; Spina and Page, 2017). This review is a brief update summarizing the chemical structure, pharmacological, and clinical details of inhaled PDE4 inhibitors.

\section{INHALED PDE4 INHIBITORS}

Several companies have disclosed data on inhaled PDE4 inhibitors. Figure 1 shows the structures of these compounds and the cell free enzyme-based potencies. Direct comparison between molecules is complicated as data was generated in different labs, using different PDE4 enzymes and experimental protocols.

\section{AWD-12-281, Elbion/GSK}

AWD-12-281 was the first moderately potent PDE4 inhibitor $\left(\mathrm{IC}_{50}=9.7 \mathrm{nM}\right)$ designed for inhaled delivery (Draheim et al., 2004; Gutke et al., 2005) and showed preclinical efficacy in a variety of species (Kuss et al., 2003). It was in clinical development for asthma and COPD although results are unavailable in the public domain. Development was discontinued due to poor efficacy in 2006.

\section{Tofimilast, Pfizer}

Tofimilast is the least potent $\left(\mathrm{IC}_{50}=140 \mathrm{nM}\right)$ of the inhaled PDE4 inhibitors reviewed (Duplantier et al., 2007). Clinical trials in mild asthma (Fregonese et al., 2007), persistent asthma (Danto et al., 2007b), GOLD stage II and III COPD patients (Danto et al., 2007a), and LPS challenged healthy subjects (Tan et al., 2007) failed to demonstrate efficacy at any dose and development has been discontinued.

\section{UK-500,001, Pfizer}

UK-500,001 is a moderately potent PDE4 inhibitor $\left(\mathrm{IC}_{50}=1 \mathrm{nM}\right)$ that showed preclinical efficacy in a variety of species (Vestbo et al., 2009), however, a clinical trial in moderate to severe COPD patients failed to demonstrate efficacy at any dose (Vestbo et al., 2009). A higher incidence of the systemic PDE4 inhibitor-related side effect of diarrhea was observed in the clinical trial despite the lack of efficacy in the lung. Interestingly, the compound was designed to have high plasma protein binding and metabolic clearance to minimize systemic exposure. It has been hypothesized that the lack of clinical activity could be due to its moderate potency and low solubility (De Savi et al., 2014). UK-500,001 was discontinued in 2006 due to lack of efficacy in COPD patients (Yeadon et al., 2010) and the results of the clinical study raised doubt about the potential of inhaled PDE4 inhibitors in COPD.

\section{GSK256066, GlaxoSmithKline}

GSK256066 is the most potent ( $\left.\mathrm{IC}_{50}=0.003 \mathrm{nM}\right)$ of the PDE4 inhibitors reviewed and has anti-inflammatory effects in preclinical animal models of pulmonary inflammation (Nials et al., 2011; Tralau-Stewart et al., 2011). Clinical trial data for GSK256066 in mild asthmatics demonstrated significantly reduced early and late asthmatic responses to allergen challenge (Singh et al., 2010), however, in mild COPD patients, no statistically significant changes in inflammatory markers were detected (Watz et al., 2013). It has been hypothesized that the concentration of free compound in the lung was too low to exert a pharmacological effect due to the low solubility and lipophilic nature of the compound (De Savi et al., 2014). Also, potentially hampering clinical development, a low therapeutic index for GSK256066 was revealed by a 14-day inhalation toxicology study in rats (Moretto et al., 2015). GSK256006 was no longer listed on the GSK development pipeline in 2012.

\section{SCH900182, Schering Plough/Merck}

SCH900182 is a highly potent PDE4 inhibitor $\left(\mathrm{IC}_{50}=0.07 \mathrm{nM}\right)$ that showed preclinical efficacy in a variety of species (Chapman et al., 2010a,b; Ting et al., 2013), yet the compound has not advanced past preclinical development.

\section{2b, AstraZeneca}

AstraZeneca designed a highly potent phenoxypyridinylamide inhaled PDE4 inhibitor $12 \mathrm{~b}\left(\mathrm{IC}_{50}=0.02 \mathrm{nM}\right)$ as a structurally differentiated back-up series to their earlier 
<smiles>O=C(Nc1c(Cl)cncc1Cl)c1ccc(OC(F)F)c(OCC2CC2)c1</smiles>

Takeda/AstraZeneca Roflumilast (Dosed p.o.) IC $_{50}=1 \mathrm{nM}$

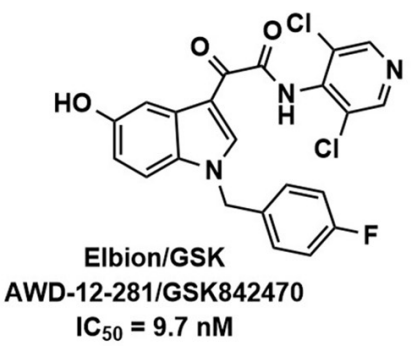<smiles>CCc1nn(C2CCCC2)c2c1CCn1c(-c3cccs3)nnc1-2</smiles>

Pfizer

Tofimilast $\mathrm{IC}_{50}=140 \mathrm{nM}$<smiles>Cc1ccc(O)c(C(=O)NC2CCC(NC(=O)c3cc(F)cnc3Oc3ccc(F)c(F)c3)CC2)c1</smiles><smiles>CCOC(=O)[C@H]1C[C@@H](NC(=O)C2CC2)CN1C(=O)c1nc(-c2ccc(OC)c3nc(C(F)(F)F)ccc23)oc1[C@H](C)N</smiles>

Schering Plough / Merck SCH900182 IC $_{50}=0.07 \mathrm{nM}$<smiles>Cc1ccc(O)c(C(=O)NC2CCC(NC(=O)c3cc(F)cnc3Oc3cccc(-c4ccc(CN5CC(C)NC(C)C5)cc4CN4CCOCC4)c3)CC2)c1</smiles>

AstraZeneca

12b

$\mathrm{IC}_{50}=0.02 \mathrm{nM}$<smiles></smiles>

$\mathrm{IC}_{50}=0.003 \mathrm{nM}$

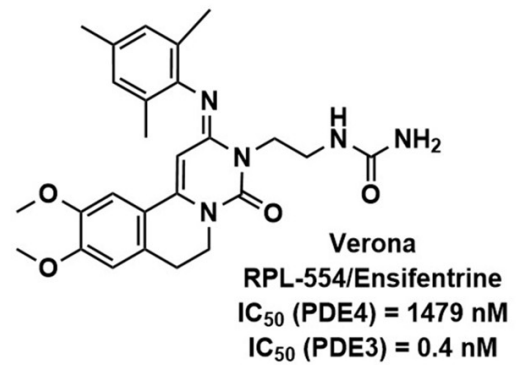

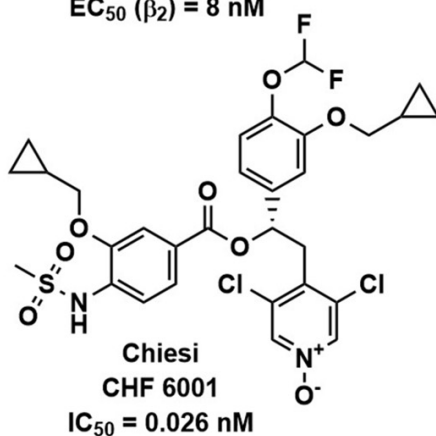

FIGURE 1 | PDE4 inhibitors. The chemical structures of roflumilast and a representative set of inhaled PDE4 inhibitors are shown with the companies that have developed them, as well as their potency $\left(\mathrm{IC}_{50}\right)$ to inhibit the PDE4 enzyme.

pyridopyrimidinedione series (De Savi et al., 2014). 12b has preclinical anti-inflammatory activity in the lung with high plasma protein binding and low bioavailability to reduce systemic side effects (De Savi et al., 2014). It is unclear if this compound is progressing into clinical trials as AstraZeneca currently has no PDE4 inhibitors in their pipeline ${ }^{1}$.

${ }^{1}$ https://www.astrazeneca.com/our-science/pipeline.html, (accessed December 1, 2019).

\section{GS-5759, Gilead}

GS-5759 is a bifunctional, moderately potent PDE4 inhibitor $\left(\mathrm{IC}_{50}=5 \mathrm{nM}\right)$ and $\beta_{2}$ adrenergic agonist $\left(\mathrm{EC}_{50}=8 \mathrm{nM}\right)$ made by linking a GSK256066 structurally related PDE4 inhibitor to an indacaterol structurally related $\beta_{2}$-agonist (Tannheimer et al., 2014; Joshi et al., 2017). Although it has shown preclinical efficacy in a variety of species (Salmon et al., 2014) this program is assumed to be discontinued as no development has been reported. 


\section{Almirall}

Almirall most recently published on two potent chemical series, the naphthyridinones (represented by compound 72 , $\mathrm{IC}_{50}=0.17 \mathrm{nM}$ ) (Roberts et al., 2018) and pyridazinones (represented by compound 50, $\mathrm{IC}_{50}=0.05 \mathrm{nM}$ ) (Gracia et al., 2016). The compounds are not planned to advance past preclinical development.

\section{Lotamilast, Eisai}

Lotamilast is a moderately potent PDE4 inhibitor $\left(\mathrm{IC}_{50}=2.8 \mathrm{nM}\right)$ that effectively suppresses LPS induced neutrophilic pulmonary inflammation when delivered to mice by dry powder insufflation (Kubota et al., 2015). Eisai licensed the drug to Roivant Sciences and lotamilast is currently in clinical development as a topical ointment for Eczema/Atopic Dermatitis.

\section{Ensifentrine/RPL554, Verona}

Ensifentrine is a dual moderately potent PDE3 $\left(\mathrm{IC}_{50}=0.4 \mathrm{nM}\right)$ and weakly potent PDE4 $\left(\mathrm{IC}_{50}=1479 \mathrm{nM}\right.$ ) inhibitor (BoswellSmith et al., 2006) that has been formulated for dry powder or nebulized delivery. Ensifentrine is included in this review as it is characterized in the literature as dual PDE3 and PDE4 inhibitor, but it is recognized that no reliable evidence is available for its ability to elicit PDE4 inhibitor like antiinflammatory activity in patients with COPD or asthma (Cazzola et al., 2019) and most of the clinical effects of ensifentrine are likely attributable to PDE3 inhibition alone. PDE3 is the primary isoenzyme in airway smooth muscle where it has effects on airway tone and PDE3 inhibitors have demonstrated acute bronchodilator effects. PDE3 is also found in cardiac and vascular tissue therefor PDE3 inhibitors are likely to have undesirable adverse systemic effects that may be minimized by inhaled delivery. An inhaled dual PDE3/PDE4 inhibitor should have both bronchodilator and anti-inflammatory effects and indeed, in preclinical animal models RPL554 has demonstrated bronchodilator and anti-inflammatory effects (Boswell-Smith et al., 2006). RPL554 has successfully undergone phase 2 studies in both asthma (Bjermer et al., 2019) and COPD (Franciosi et al., 2013; Singh et al., 2018) but has currently only demonstrated significant bronchodilator effects. Verona is planning to begin a final-stage clinical evaluation for nebulized RPL554 treatment of patients with severe COPD in 2020.

\section{CHF 6001, Chiesi}

CHF 6001 is a highly potent PDE4 inhibitor $\left(\mathrm{IC}_{50}=0.026 \mathrm{nM}\right)$ that showed preclinical efficacy in a variety of species (Moretto et al., 2015; Villetti et al., 2015). It is well tolerated in humans (Mariotti et al., 2018). In a double blind, placebo controlled, three-way crossover study, 36 atopic asthmatics received $\mathrm{CHF}$ 6001 doses of 400 or $1200 \mu \mathrm{g}$ inhaled once daily for 9 days. Allergen challenges were performed on day 9. Both CHF 6001 doses significantly inhibited allergen induced late asthmatic response (Singh et al., 2016). CHF 6001 was well tolerated, with similar numbers of adverse events in each treatment period. In a double-blind, placebo-controlled, three-way crossover study in 61 patients with COPD and chronic bronchitis (already treated with inhaled triple therapy: inhaled corticosteroid, long-acting muscarinic antagonist, and long-acting $\beta_{2}$-agonist) received $\mathrm{CHF}$ 6001 doses of 800 or $1600 \mu \mathrm{g}$ inhaled twice daily for 32 days. Multiple biomarkers of airway inflammation in induced sputum were significantly reduced, demonstrating additional lung antiinflammatory activity on top of standard of care (Singh et al., 2019). Both doses of CHF 6001 were safe and the incidence of gastrointestinal adverse effects was comparable to placebo. CHF 6001 is currently in phase IIb clinical trials for the treatment of COPD (Stellari et al., 2019). Chiesi also has recently published on two structurally differentiated backup series to CHF 6001 (Armani et al., 2014; Carzaniga et al., 2017). The clinical data for CHF 6001 demonstrates anti-inflammatory effects with minimal systemic side effects, likely due to the high lung relative to systemic exposure provided by inhaled delivery and favorable LARBS/HARBS ratio. The results of the phase III clinical trials are eagerly awaited.

\section{DISCUSSION}

PDE4 inhibitors block the breakdown of cAMP and decrease airway inflammation. Use of PDE4 inhibitors has been limited by mechanism based systemic side effects (nausea, diarrhea, and headache). Inhaled administration of PDE4 inhibitors for the treatment of respiratory diseases applies the drug directly to the site of action, the lungs, and minimizes the systemic exposure. This is an important advantage that can greatly increase the therapeutic index of a drug. Many of the inhaled PDE4 inhibitors highlighted in this review are discontinued (Table 1) and have produced only modest beneficial clinical effects in respiratory disease patients. Only CHF 6001 is currently advancing through clinical development. None of the discontinued inhaled compounds have convincingly covered the target, thus the hypothesis of increased efficacy with avoidance of systemic adverse events was not adequately tested. Since oral roflumilast does demonstrate clinical efficacy, it is possible that

TABLE 1 | Discontinued inhaled PDE4 inhibitors.

\begin{tabular}{lll}
\hline $\begin{array}{l}\text { Name/ } \\
\text { Company }\end{array}$ & Disease indications & $\begin{array}{l}\text { Development stage (Last } \\
\text { development reported) }\end{array}$ \\
\hline $\begin{array}{l}\text { AWD-12-281 } \\
\text { Elbion/GSK }\end{array}$ & $\begin{array}{l}\text { COPD } \\
\text { Asthma }\end{array}$ & $\begin{array}{l}\text { Phase II (2006) } \\
\text { Phase II (2003) }\end{array}$ \\
Pfimilast & COPD & Phase II (2007) \\
UK-500,001 & Asthma & Phase II (2007) \\
Pfizer & COPD & Phase II (2009) \\
GSK256066 & Phase II (2013) \\
GlaxoSmith Kline & Asthma & Phase II (2010) \\
$12 b$ & COPD & Discovery (2014) \\
AstraZeneca & & \\
$\begin{array}{l}\text { SCH900182 } \\
\text { Schering Plough/Merck }\end{array}$ & Asthma & Discovery (2013) \\
GS-5759 & COPD & \\
Gilead & & Discovery (2017) \\
& &
\end{tabular}


a systemic effect of PDE4 inhibitors is required, possibly to suppress cytokine production or cell activity in inflammatory cells before they reach the lung. The recent successful results with CHF 6001, suggest that the systemic biology of PDE4 is less relevant than the lung biology for clinical efficacy in inflammatory respiratory diseases.

CHF 6001 is currently the only inhaled PDE4 inhibitor advancing through clinical development and already has promising results in phase II clinical trials in asthma (Singh et al., 2016) and COPD (Singh et al., 2019). The clinical data for CHF 6001 demonstrates anti-inflammatory effects while minimizing the typical PDE4 inhibitor induced systemic side effects. This is likely due to the high lung relative to systemic exposure provided by inhaled delivery and demonstrates the therapeutic index of a PDE4 inhibitor can be increased by inhaled delivery.

Inhaled PDE4 inhibitors offer an intriguing new class of treatment for inflammatory respiratory diseases. Oral PDE4 inhibitors like roflumilast only have explored the lower end of the efficacy dose-response curve in man. Assuming toleration issues can be overcome by inhaled delivery, the maximum therapeutic potential in respiratory diseases of PDE4 inhibition will be determined. The pharmacology of inhaled PDE4 inhibitors should minimize side effects driven

\section{REFERENCES}

Ariga, M., Neitzert, B., Nakae, S., Mottin, G., Bertrand, C., Pruniaux, M. P., et al. (2004). Nonredundant function of phosphodiesterases $4 \mathrm{D}$ and $4 \mathrm{~B}$ in neutrophil recruitment to the site of inflammation. J. Immunol. 173, 7531-7538. doi: 10. 4049/jimmunol.173.12.7531

Armani, E., Amari, G., Rizzi, A., Fanti, R. D., Ghidini, E., Capaldi, C., et al. (2014). Novel class of benzoic acid ester derivatives as potent PDE4 inhibitors for inhaled administration in the treatment of respiratory diseases. J. Med. Chem. 57, 793-816. doi: 10.1021/jm401549m

Baillie, G. S., Tejeda, G. S., and Kelly, M. P. (2019). Therapeutic targeting of $3^{\prime}, 5^{\prime}$ cyclic nucleotide phosphodiesterases: inhibition and beyond. Nat. Rev. Drug. Discov. 18, 770-796. doi: 10.1038/s41573-019-0033-4

Bjermer, L., Abbott-Banner, K., and Newman, K. (2019). Efficacy and safety of a first-in-class inhaled PDE3/4 inhibitor (ensifentrine) vs salbutamol in asthma. Pulm. Pharmacol. Ther. 58:101814. doi: 10.1016/j.pupt.2019.101814

Boswell-Smith, V., Spina, D., Oxford, A. W., Comer, M. B., Seeds, E. A., and Page, C. P. (2006). The pharmacology of two novel long-acting phosphodiesterase 3/4 inhibitors, RPL554 [9,10-dimethoxy-2(2,4,6-trimethylphenylimino)-3-(ncarbamoyl-2-aminoethyl)-3,4,6,7-tetrahydro-2H-pyrimido[6,1-a]isoquinolin4-one] and RPL565 [6,7-dihydro-2-(2,6-diisopropylphenoxy)-9,10-dimethoxy4H-pyrimido[6,1-a]isoquinolin-4-one]. J. Pharmacol. Exp. Ther. 318, 840-848. doi: 10.1124/jpet.105.099192

Calverley, P. M. A., Rabe, K. F., Goehring, U.-M., Kristiansen, S., Fabbri, L. M., Martinez, F. J., et al. (2009). Roflumilast in symptomatic chronic obstructive pulmonary disease: two randomised clinical trials. Lancet 374, 685-694. doi: 10.1016/S0140-6736(09)61255-1

Carzaniga, L., Amari, G., Rizzi, A., Capaldi, C., De Fanti, R., Ghidini, E., et al. (2017). Discovery and optimization of thiazolidinyl and pyrrolidinyl derivatives as inhaled PDE4 inhibitors for respiratory diseases. J. Med. Chem. 60, 1002610046. doi: 10.1021/acs.jmedchem.7b01044

Cazzola, M., Calzetta, L., Rogliani, P., and Matera, M. G. (2016). The discovery of roflumilast for the treatment of chronic obstructive pulmonary disease. Expert Opin. Drug Discov. 11, 733-744. doi: 10.1080/17460441.2016.1184642

Cazzola, M., Calzetta, L., Rogliani, P., and Matera, M. G. (2019). Ensifentrine (RPL554): an investigational PDE3/4 inhibitor for the treatment of COPD. Expert Opin. Inv. Drug 28, 827-833. doi: 10.1080/13543784.2019.1661990

Chapman, R. W., House, A., Richard, J., Fernandez, X., Jones, H., Prelusky, D., et al. (2010a). Pharmacology of SCH900182, a potent, selective inhibitor of by biology outside the lung. Their efficacy in asthma and COPD suggest PDE4 inhibitors will reduce inflammation regardless of the level of type 2 inflammation. Their efficacy on top of standard of care in COPD suggest they could be combined with inhaled steroids and bronchodilators. Answers to the questions surrounding efficacy and safety of an inhaled PDE4 inhibitor are eagerly awaited in phase III clinical trials.

\section{AUTHOR CONTRIBUTIONS}

JP contributed to conception, design, data interpretation, and drafting of manuscript.

\section{ACKNOWLEDGMENTS}

The author thanks JM, Mark Giembycz, and Daniela Mokra for the invitation to contribute to the Phosphodiesterases as Drug Targets in Airway and Inflammatory Diseases research topic and Brian Bennett for proofreading the manuscript and helpful discussions.

PDE4 for inhaled administration. Am. J. Respir. Crit. Care Med. 181:A5671. doi: 10.1164/ajrccm-conference.2010.181.1_MeetingAbstracts.A5671

Chapman, R. W., House, A., Richard, J., Prelusky, D., Lamca, J., Wang, P., et al. (2010b). Pharmacology of a potent and selective inhibitor of PDE4 for inhaled administration. Eur. J. Pharmacol. 643, 274-281. doi: 10.1016/j.ejphar.2010.06. 054

Danto, S., Wei, G., and Gill, J. (2007a). A randomized, double-blind, placebocontrolled, parallel group, six-week study of the efficacy and safety of tofimilast dry powder for inhalation (DPI) in adults with COPD. Am. J. Respir. Crit. Care Med. 175:A131. doi: 10.1186/s12931-017-0647-1

Danto, S., Wei, G., and Gill, J. (2007b). A randomized, double-blind, placebocontrolled, parallel group, six-week study of the efficacy and safety of tofimilast dry powder for inhalation (DPI) in adults with persistent asthma. Am. J. Respir. Crit. Care Med. 175:A485.

De Savi, C., Cox, R. J., Warner, D. J., Cook, A. R., Dickinson, M. R., McDonough, A., et al. (2014). Efficacious inhaled PDE4 inhibitors with low emetic potential and long duration of action for the treatment of COPD. J. Med. Chem. 57, 4661-4676. doi: 10.1021/jm5001216

Draheim, R., Egerland, U., and Rundfeldt, C. (2004). Anti-inflammatory potential of the selective phosphodiesterase 4 inhibitor N-(3,5-dichloro-pyrid-4-yl)-[1(4-fluorobenzyl)-5-hydroxy-indole-3-yl]-glyoxylic acid amide (AWD 12-281), in human cell preparations. J. Pharmacol. Exp. Ther. 308, 555-563. doi: 10.1124/ jpet.103.059097

Duplantier, A. J., Bachert, E. L., Cheng, J. B., Cohan, V. L., Jenkinson, T. H., Kraus, K. G., et al. (2007). SAR of a series of 5,6-dihydro-(9H)-pyrazolo[3,4c]-1,2,4-triazolo[4,3-alpha]pyridines as potent inhibitors of human eosinophil phosphodiesterase. J. Med. Chem. 50, 344-349. doi: 10.1021/jm0 $60904 \mathrm{~g}$

Fabbri, L. M., Calverley, P. M. A., Izquierdo-Alonso, J. L., Bundschuh, D. S., Brose, M., Martinez, F. J., et al. (2009). Roflumilast in moderate-to-severe chronic obstructive pulmonary disease treated with longacting bronchodilators: two randomised clinical trials. Lancet 374, 695-703. doi: 10.1016/S0140-6736(09) 61252-6

Fox, D. III, Burgin, A. B., and Gurney, M. E. (2014). Structural basis for the design of selective phosphodiesterase 4B inhibitors. Cell. Signal. 26, 657-663. doi: 10.1016/j.cellsig.2013.12.003

Franciosi, L. G., Diamant, Z., Banner, K. H., Zuiker, R., Morelli, N., Kamerling, I. M., et al. (2013). Efficacy and safety of RPL554, a dual PDE3 and PDE4 inhibitor, in healthy volunteers and in patients with asthma or chronic 
obstructive pulmonary disease: findings from four clinical trials. Lancet Respir. Med. 1, 714-727. doi: 10.1016/s2213-2600(13)70187-5

Fregonese, L., Grootendorst, D., Gaum, S., Wei, C., Bennetts, M., Ward, J., et al. (2007). The inhaled PDE4 inhibitor tofimilast does not inhibit airway responses to allergen and histamine. Am. J. Respir. Crit. Care Med. 175: A486.

Gracia, J., Buil, M. A., Castro, J., Eichhorn, P., Ferrer, M., Gavalda, A., et al. (2016). Biphenyl pyridazinone derivatives as inhaled PDE4 inhibitors: structural biology and structure-activity relationships. J. Med. Chem. 59, 10479-10497. doi: 10.1021/acs.jmedchem.6b00829

Gutke, H.-J., Guse, J.-H., Khobzaoui, M., Renukappa-Gutke, T., and Burnet, M. (2005). AWD-12-281 (inhaled) (elbion/GlaxoSmithKline). Curr. Opin. Investig. Drugs 6, 1149-1158.

Houslay, M. D., Schafer, P., and Zhang, K. Y. J. (2005). Keynote review: phosphodiesterase-4 as a therapeutic target. Drug Discov. Today 10, 1503-1519. doi: 10.1016/S1359-6446(05)03622-6

Joshi, T., Yan, D., Hamed, O., Tannheimer, S. L., Phillips, G. B., Wright, C. D., et al. (2017). GS-5759, a bifunctional $\beta 2$-adrenoceptor agonist and phosphodiesterase 4 inhibitor for chronic obstructive pulmonary disease with a unique mode of action: effects on gene expression in human airway epithelial cells. J. Pharmacol. Exp. Ther. 360, 324-340. doi: 10.1124/jpet.116.23 7743

Krzanowski, J. J., and Polson, J. B. (1988). Mechanism of action of methylxanthines in asthma. J. Allergy Clin. Immunol. 82, 143-145. doi: 10.1016/0091-6749(88) 90992-x

Kubota, S., Watanabe, M., Shirato, M., Okuno, T., Higashimoto, I., Machida, K., et al. (2015). An inhaled phosphodiesterase 4 inhibitor E6005 suppresses pulmonary inflammation in mice. Eur. J. Pharmacol. 768, 41-48. doi: 10.1016/ j.ejphar.2015.10.013

Kuss, H., Hoefgen, N., Johanssen, S., Kronbach, T., and Rundfeldt, C. (2003). In vivo efficacy in airway disease models of $\mathrm{N}$-(3,5-dichloropyrid4-yl)-[1-(4-fluorobenzyl)-5-hydroxy-indole-3-yl]-glyoxylic acid amide (AWD 12-281), a selective phosphodiesterase 4 inhibitor for inhaled administration. J. Pharmacol. Exp. Ther. 307, 373-385. doi: 10.1124/jpet.103.05 3942

Li, H., Zuo, J., and Tang, W. (2018). Phosphodiesterase-4 inhibitors for the treatment of inflammatory diseases. Front. Pharmacol. 9:1048. doi: 10.3389/ fphar.2018.01048

Louw, C., Williams, Z., Venter, L., Leichtl, S., Schmid-Wirlitsch, C., Bredenbröker, D., et al. (2007). Roflumilast, a phosphodiesterase 4 inhibitor, reduces airway hyperresponsiveness after allergen challenge. Respiration 74, 411-417. doi: 10. $1159 / 000095677$

Mariotti, F., Govoni, M., Lucci, G., Santoro, D., and Nandeuil, M. A. (2018). Safety, tolerability, and pharmacokinetics of single and repeat ascending doses of CHF6001, a novel inhaled phosphodiesterase-4 inhibitor: two randomized trials in healthy volunteers. Int. J. Chron. Obstruct. Pulmon. Dis. 13, 3399-3410. doi: $10.2147 /$ COPD.S174156

Matera, M. G., Rogliani, P., Calzetta, L., and Cazzola, M. (2014). Phosphodiesterase inhibitors for chronic obstructive pulmonary disease: what does the future hold? Drugs 74, 1983-1992. doi: 10.1007/s40265-014-0303-8

Moretto, N., Caruso, P., Bosco, R., Marchini, G., Pastore, F., Armani, E., et al. (2015). CHF6001 I: a novel highly potent and selective phosphodiesterase 4 inhibitor with robust anti-inflammatory activity and suitable for topical pulmonary administration. J. Pharmacol. Exp. Ther. 352, 559-567. doi: 10.1124/ jpet.114.220541

Mulhall, A. M., Droege, C. A., Ernst, N. E., Panos, R. J., and Zafar, M. A. (2015). Phosphodiesterase 4 inhibitors for the treatment of chronic obstructive pulmonary disease: a review of current and developing drugs. Expert Opin. Inv. Drug 24, 1597-1611. doi: 10.1517/13543784.2015.1094054

Nials, A. T., Tralau-Stewart, C. J., Gascoigne, M. H., Ball, D. I., Ranshaw, L. E., and Knowles, R. G. (2011). In vivo characterization of GSK256066, a high-affinity inhaled phosphodiesterase 4 inhibitor. J. Pharmacol. Exp. Ther. 337, 137-144. doi: 10.1124/jpet.110.173641

Page, C. P. (2014). Phosphodiesterase inhibitors for the treatment of asthma and chronic obstructive pulmonary disease. Int. Arch. Allergy Immunol. 165, 152-164. doi: 10.1159/000368800

Rall, T. W., and Sutherland, E. W. (1958). Formation of a cyclic adenine ribonucleotide by tissue particles. J. Biol. Chem. 232, 1065-1076.

Roberts, R. S., Sevilla, S., Ferrer, M., Taltavull, J., Hernández, B., Segarra, V., et al. (2018). 4-Amino-7,8-dihydro-1,6-naphthyridin-5(6H)-ones as inhaled phosphodiesterase type 4 (PDE4) inhibitors: structural biology and structureactivity relationships. J. Med. Chem. 61, 2472-2489. doi: 10.1021/acs.jmedchem. $7 \mathrm{~b} 01751$

Robichaud, A., Stamatiou, P. B., Jin, S. L., Lachance, N., MacDonald, D., Laliberte, F., et al. (2002). Deletion of phosphodiesterase 4D in mice shortens alpha(2)adrenoceptor-mediated anesthesia, a behavioral correlate of emesis. J. Clin. Invest. 110, 1045-1052. doi: 10.1172/jci15506

Salmon, M., Tannheimer, S. L., Gentzler, T. T., Cui, Z. H., Sorensen, E. A., Hartsough, K. C., et al. (2014). The in vivo efficacy and side effect pharmacology of GS-5759, a novel bifunctional phosphodiesterase 4 inhibitor and long-acting beta 2-adrenoceptor agonist in preclinical animal species. Pharmacol. Res. Perspect. 2:e00046. doi: 10.1002/prp2.46

Singh, D., Abbott-Banner, K., Bengtsson, T., and Newman, K. (2018). The shortterm bronchodilator effects of the dual phosphodiesterase 3 and 4 inhibitor RPL554 in COPD. Eur. Respir. J. 52:1801074. doi: 10.1183/13993003.010742018

Singh, D., Beeh, K. M., Colgan, B., Kornmann, O., Leaker, B., Watz, H., et al. (2019). Effect of the inhaled PDE4 inhibitor CHF6001 on biomarkers of inflammation in COPD. Respir. Res. 20:180. doi: 10.1186/s12931-019$1142-7$

Singh, D., Leaker, B., Boyce, M., Nandeuil, M. A., Collarini, S., Mariotti, F., et al. (2016). A novel inhaled phosphodiesterase 4 inhibitor (CHF6001) reduces the allergen challenge response in asthmatic patients. Pulm. Pharmacol. Ther. 40, 1-6. doi: 10.1016/j.pupt.2016.06.011

Singh, D., Petavy, F., Macdonald, A. J., Lazaar, A. L., and O'Connor, B. J. (2010). The inhaled phosphodiesterase 4 inhibitor GSK256066 reduces allergen challenge responses in asthma. Respir. Res. 11:26. doi: 10.1186/1465-9921$11-26$

Spina, D., and Page, C. P. (2017). "Xanthines and phosphodiesterase inhibitors," in Pharmacology and Therapeutics of Asthma and COPD, eds C. P. Page, and P. J. Barnes (Cham: Springer International Publishing), 63-91. doi: 10.1007/ 164_2016_71

Stellari, F. F., Sala, A., Ruscitti, F., Buccellati, C., Allen, A., Risé, P., et al. (2019). CHF6001 inhibits NF-кB activation and neutrophilic recruitment in LPSinduced lung inflammation in mice. Front. Pharmacol. 10:1337. doi: 10.3389/ fphar.2019.01337

Tan, E., Ward, J. K., Bennets, M., Wei, G. C., Hidi, R., Greenaway, S. D., et al. (2007). A study to investigate the effect of the phosphodiesterase Type 4 (PDE4) inhibitor, Tofimilast on induced sputum and systemic inflammatory markers following inhaled lipopolysaccharide (LPS) challenge in healthy subjects. Am. J. Respir. Crit. Care Med. 175:A132.

Tannheimer, S. L., Sorensen, E. A., Cui, Z. H., Kim, M., Patel, L., Baker, W. R., et al. (2014). The in vitro pharmacology of GS-5759, a novel bifunctional phosphodiesterase 4 inhibitor and long acting beta2-adrenoceptor agonist. J. Pharmacol. Exp. Ther. 349, 85-93. doi: 10.1124/jpet.113.21 0997

Tenor, H., Hatzelmann, A., Beume, R., Lahu, G., Zech, K., and Bethke, T. D. (2011). "Pharmacology, clinical efficacy, and tolerability of phosphodiesterase-4 inhibitors: impact of human pharmacokinetics," in Phosphodiesterases as Drug Targets, eds S. H. Francis, M. Conti, and M. D. Houslay (Berlin: Springer), 85-119. doi: 10.1007/978-3-642-17969-3_3

Ting, P. C., Lee, J. F., Kuang, R., Cao, J., Gu, D., Huang, Y., et al. (2013). Discovery of oral and inhaled PDE4 inhibitors. Bioorg. Med. Chem. Lett. 23, 5528-5532. doi: 10.1016/j.bmcl.2013.08.056

Tralau-Stewart, C. J., Williamson, R. A., Nials, A. T., Gascoigne, M., Dawson, J., Hart, G. J., et al. (2011). GSK256066, an exceptionally high-affinity and selective inhibitor of phosphodiesterase 4 suitable for administration by inhalation: in vitro, kinetic, and in vivo characterization. J. Pharmacol. Exp. Ther. 337, 145-154. doi: 10.1124/jpet.110.173690

van Schalkwyk, E., Strydom, K., Williams, Z., Venter, L., Leichtl, S., SchmidWirlitsch, C., et al. (2005). Roflumilast, an oral, once-daily phosphodiesterase 4 inhibitor, attenuates allergen-induced asthmatic reactions. J. Allergy Clin. Immunol. 116, 292-298. doi: 10.1016/j.jaci.2005.04.023

Vestbo, J., Tan, L., Atkinson, G., Ward, J., and Uk, G. S. T. (2009). A controlled trial of 6-weeks' treatment with a novel inhaled phosphodiesterase type-4 inhibitor in COPD. Eur. Respir. J. 33, 1039-1044. doi: 10.1183/09031936.0006 8908

Villetti, G., Carnini, C., Battipaglia, L., Preynat, L., Bolzoni, P. T., Bassani, F., et al. (2015). CHF6001 II: a novel phosphodiesterase 4 inhibitor, suitable for topical pulmonary administration-in vivo preclinical pharmacology profile 
defines a potent anti-inflammatory compound with a wide therapeutic window. J. Pharmacol. Exp. Ther. 352, 568-578. doi: 10.1124/jpet.114.22 0558

Watz, H., Mistry, S. J., and Lazaar, A. L. (2013). Safety and tolerability of the inhaled phosphodiesterase 4 inhibitor GSK256066 in moderate COPD. Pulm. Pharmacol. Ther. 26, 588-595. doi: 10.1016/j.pupt.2013. 05.004

Yeadon, M., Clarke, N., and Ward, J. (2010). "Phosphodiesterase type 4 (PDE4) inhibition: the search for effective therapy with minimal side effects," in New Drugs and Targets for Asthma and COPD, eds T. Hansel, and P. Barnes (Basel: Karger), 268-278.
Conflict of Interest: JP is an employee of Amgen Inc., which provides financial support for his work. The funder was not involved in the collection, analysis, interpretation of data, the writing of this article or the decision to submit it for publication.

Copyright $\odot 2020$ Phillips. This is an open-access article distributed under the terms of the Creative Commons Attribution License (CC BY). The use, distribution or reproduction in other forums is permitted, provided the original author(s) and the copyright owner(s) are credited and that the original publication in this journal is cited, in accordance with accepted academic practice. No use, distribution or reproduction is permitted which does not comply with these terms. 